\title{
REDUCTION OF HYPOXIC PULMONARY VASOCONSTRICTION BY NITROUS OXIDE ADMINISTRATION IN THE ISOLATED PERFUSED CAT LUNG
}

\author{
J.B. Hurtig, A.R. TAit, L. LoH, AND M.K. Sykes
}

IT IS GENERALLY ACCEPTED that there is an increase in the alveolar-arterial $\mathrm{Po}_{2}$ difference during general anaesthesia ${ }^{1,2}$ and that changes in lung mechanics, leading to a decrease in functional residual capacity, airway closure and alveolar hypoxia, contribute to this phenomenon. ${ }^{3,4}$ It has also been demonstrated that alveolar hypoxia produces pulmonary vasoconstriction in both the healthy and diseased lung. ${ }^{5}$ This is believed to be a protective mechanism which tends to divert pulmonary capillary blood flow away from under-ventilated and hypoxic areas of lung to better oxygenated lung units. It has recently been postulated that inhalational anaesthetic agents may depress this mechanism, so that there is an increased blood flow to poorly ventilated lung units with a resultant increase in arterial hypoxaemia. ${ }^{6}$

It is often extremely difficult to draw firm conclusions from studies of the pulmonary circulation in the intact animal or patient. For this reason the present studies were performed in the isolated perfused lung of the cat. In this preparation the lungs are perfused at constant flow, perfusate viscosity is constant and transpulmonary and left atrial pressures are controlled. Under these circumstances there is a direct relationship between changes in pulmonary artery pressure and pulmonary vascular resistance. This paper documents the direct effects of nitrous oxide on pulmonary vascular resistance and on the pulmonary vasoconstrictor response to alveolar hypoxia.

\section{Method}

The experiments were carried out on 15 cats ranging in weight from 1.4 to $5.0 \mathrm{~kg}$. Technically satisfactory preparations with demonstration of hypoxic pulmonary vasoconstriction were obtained in ten cats.

Anaesthesia was induced with intravenous pentobarbitone (approximately $30 \mathrm{mg} / \mathrm{kg}$ ) and a tracheostomy was performed. The lungs were then ventilated with a constant-volume second-stage paediatric ventilator, driven in the first instance by a Cape ventilator (Figure 1). The bellows of the second-stage attachment aspirated gases from a $T$-piece reservoir connected to the fresh gas inflow. The respiratory rate was set at 20 breaths per minute and the tidal volume adjusted

'J.B. Hurtig, M.D., F.R.C.P.(C); A.R. Tait, B.Sc.; L. Loh, M.B., B.S., F.F.A.R.C.S.; and M.K. Sykes, M.A., M.B., B.Chir., F.F.A.R.C.S. Department of Anaesthetics, Royal Postgraduate Medical School, London, England.

-Present address: Department of Anaesthesia, 4th Floor Link, Ottawa Civic Hospital and The University of Ottawa, 1053 Carling Avenue, Ottawa, Ontario, Canada, K1Y 4 E9.

Canad. Anaesth. Soc. J., vol. 24, no. 5, September 1977 

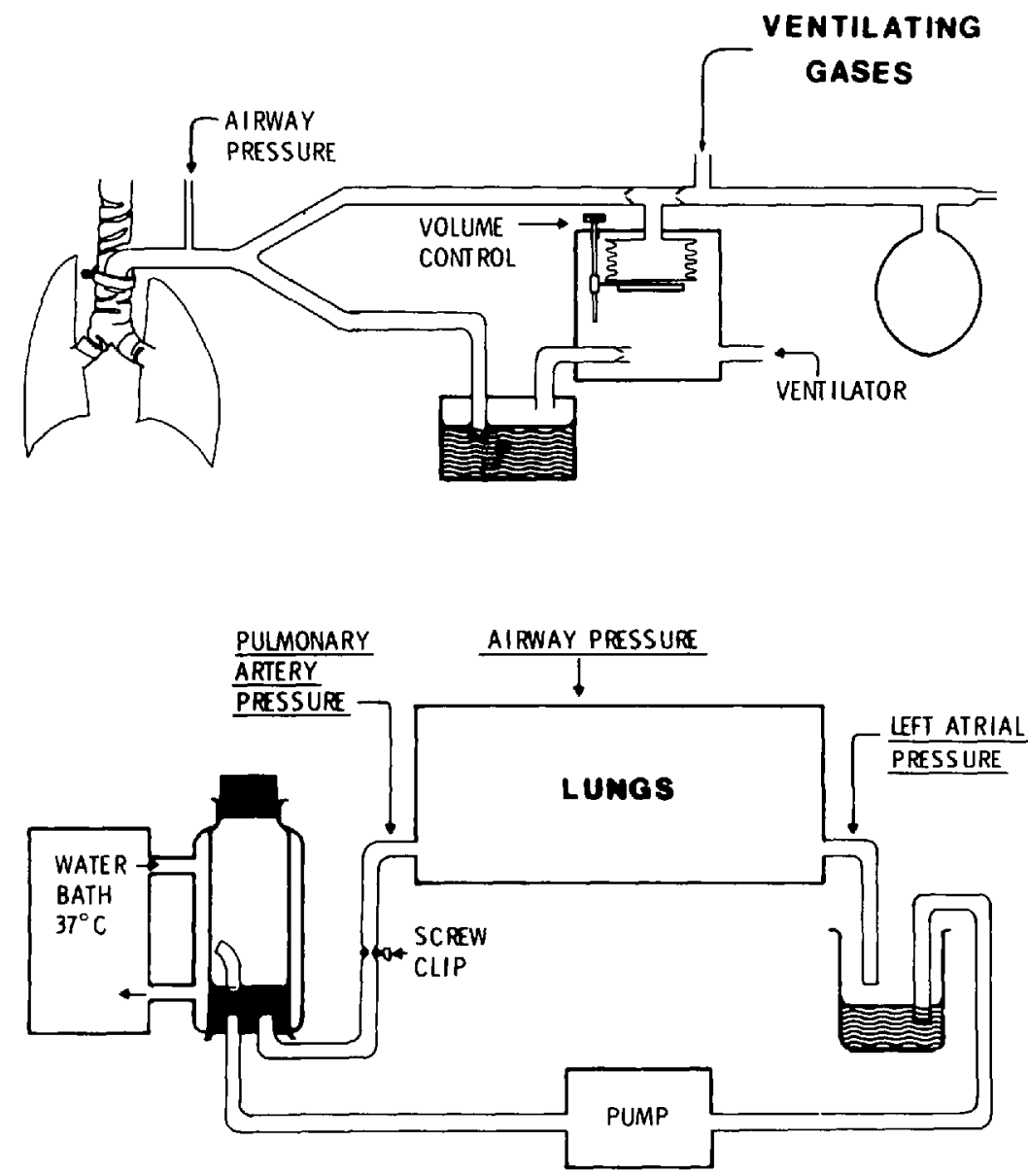

Figure 1. Isolated perfused cat lung ventilation and perfusion circuits. Above: Second stage constant volume ventilation circuit with under-water positive end-expiratory pressure device. Below: Perfusion circuit.

to produce an end-tidal carbon dioxide concentration of between 4 and 5 per cent. Air was used as the ventilating gas until the lungs were isolated, at which time 5 per cent carbon dioxide was added to maintain a normal $\mathrm{PcO}_{2}$ during perfusion. An end-expiratory pressure of 2 to $3 \mathrm{~cm} \mathrm{H} \mathrm{H}_{2} \mathrm{O}$ was applied when the chest was open to prevent atelectasis and the airway pressure was recorded continuously with the other pressure traces.

The perfusion circuit was constructed of silicone rubber tubing, with glass reservoirs and nylon connectors. The whole circuit was carefully cleaned between perfusions to prevent any extraneous materials from interfering with the response of the preparation to hypoxia. ${ }^{7}$ To establish the perfusion, the heart was exposed by a median sternotomy, a $3 \mathrm{~mm}$ i.d. cannula was inserted into the right atrium and heparin $3 \mathrm{mg} / \mathrm{kg}$ was injected through the cannula and allowed to circulate. 
The animal was then rapidly exsanguinated into the perfusion circuit. In a few small cats 10 to $20 \mathrm{ml}$ of dextran (dextran 110 injection B.P. in 0.9 per cent sodium chloride) were added to increase the volume of perfusate to a workable level. After exsanguination the right atrial cannula was removed and the pulmonary artery and aorta were cross-clamped just proximal to the pulmonary artery bifurcation in order to prevent air emboli from entering the lungs. The pulmonary artery was then cannulated through the wall of the right ventricle. A second cannula was inserted into the left atrium through the left ventricular wall. Both cannulae were firmly anchored by tapes passed round the pulmonary artery and round both ventricles. All the air bubbles were aspirated from the pulmonary artery cannula and this line was connected to the perfusion circuit. The left atrial cannula was then led into a drainage reservoir, which was connected in turn to an occlusive roller pump previously flow-calibrated with blood. The pulsatile flow from the roller pump was smoothed by the air in the heat exchanger and by a screw clamp on the line leading to the pulmonary artery cannula. Blood was therefore drained from the lungs through the left atrial cannula and pumped from the left atrial reservoir, through a heat exchanger with a water bath temperature of $37^{\circ} \mathrm{C}$, and back into the lungs through the pulmonary artery (Figure 1).

As soon as the preparations were complete, ischaemia time was noted and the perfusion commenced. The flow rate was gradually increased to produce a pulmonary artery pressure in the range of 15 to $25 \mathrm{~mm} \mathrm{Hg}$ with the left atrial pressure set between 3 and $5 \mathrm{~mm} \mathrm{Hg}$. When the perfusion was established the lungs were ventilated with 5 per cent carbon dioxide in air and sodium bicarbonate was added to bring the $\mathrm{pH}$ to between 7.35 and 7.45 . The $\mathrm{pH}$ was checked regularly during the perfusion and any metabolic acidosis was corrected with sodium bicarbonate as necessary. Pulmonary artery, left atrial and airway pressures were measured utilizing Consolidated Dynamics transducers and Devices Ltd. heated-stylus recorders.

\section{Protocol}

After steady-state conditions had been achieved, a gas mixture containing 3 per cent oxygen and 5 per cent carbon dioxide in nitrogen was substituted as the ventilating gas for two minutes to elicit a control hypoxic pressor response. When the pulmonary artery pressure had returned to baseline levels, a mixture of 25 per cent nitrous oxide, 5 per cent carbon dioxide, 21 per cent oxygen and nitrogen was introduced for eight minutes. Then 25 per cent nitrous oxide, 5 per cent carbon dioxide, with 3 per cent oxygen and nitrogen was substituted for two minutes to test the hypoxic pressor response in the presence of this concentration of nitrous oxide. The original mixture of 5 per cent carbon dioxide in air was then re-introduced and baseline levels were achieved. After an interval of approximately ten minutes the control response to two minutes of 3 per cent oxygen in 5 per cent carbon dioxide and nitrogen was measured and if the hypoxic pressor response was present, the experiment was continued by repeating the sequence with gas mixtures containing 50 per cent and 75 per cent nitrous oxide. 


\section{Calculations}

At each stage of the experiment pulmonary vascular resistance (PVR) was calculated from the formula:

$$
\operatorname{PVR}=(\mathbf{P} \overline{\mathrm{pa}}-\mathrm{P} \overline{\mathrm{a}}) \times 100 / \bar{Q}(\mathrm{~mm} \mathrm{Hg} / 100 \mathrm{ml} / \mathrm{min})
$$

where $\mathrm{Ppa}=$ Pulmonary artery pressure $(\mathrm{mm} \mathrm{Hg})$

$P T \bar{a}=$ Left atrial pressure $(\mathrm{mm} \mathrm{Hg})$

$\dot{\mathrm{Q}}=$ Pulmonary blood flow $(\mathrm{ml} / \mathrm{min})$

'The following comparisons were then made using Students' paired t-test:

1. PVR during the administration of nitrous oxide compared with means of PVR before and after.

2. Percentage increases in PVR in response to hypoxia during the administration of nitrous oxide compared with means of percentage increases in response to hypoxia before and after the administration of nitrous oxide. No nitrous oxide observation was included in the results unless a hypoxic pressor response could be demonstrated following washout of the anaesthetic agent.

\section{Results}

There were ten satisfactory perfusions in which an active hypoxic pressor response was demonstrated. In four animals the hypoxic pressor response did not persist throughout the experiment and only the initial measurements are included. A further two animals were tested only at the 75 per cent nitrous oxide level. Since this type of preparation tends to deteriorate with time, all the observations made during the administration of nitrous oxide were compared with the means of the observations made before and after the administration of nitrous oxide.

Details of the successful perfusions are given in Table I. Ischaemia time averaged 12.9 minutes and total perfusion time four hours and 34 minutes. There were no significant changes in airway pressure or left atrial pressure throughout these experiments.

Changes in pulmonary vascular resistance during the administration of nitrous oxide are shown in Table II. There was a significant reduction in pulmonary vascular resistance during the administration of all three concentrations of nitrous oxide.

The percentage increases in pulmonary artery pressure in response to the inhalation of 3 per cent oxygen are shown in Table III and Figure 2. It can be seen that during the administration of 50 per cent and 75 per cent nitrous oxide, the percentage increase in pulmonary artery pressure in response to the hypoxic stimulus was significantly lower than the mean of the percentage increases before and after the administration of nitrous oxide. A typical response is illustrated in Figure 3.

\section{Discussion}

The results indicate that there was a significant reduction in pulmonary vascular resistance during the administration of all three concentrations of nitrous oxide 
TABLE I

Details of Perfusions

\begin{tabular}{lccccc}
\hline \hline & Weight $(\mathrm{kg})$ & $\begin{array}{c}\text { Ischaemia } \\
\text { time }(\mathrm{min})\end{array}$ & $\begin{array}{c}\text { Perfusion } \\
\text { time }(\mathrm{min})\end{array}$ & $\begin{array}{c}\text { Flow rate } \\
(\mathrm{m} / \mathrm{kg} / \mathrm{min})\end{array}$ & $\begin{array}{c}\text { Left atrial } \\
\text { pressure (mm } \mathrm{Hg})\end{array}$ \\
\hline $\mathrm{m}$ (SD) & $3.1(1.1)$ & $12.9(6.3)$ & $274(67.6)$ & $44.6(15.1)$ & $3.2(1.1)$ \\
$\mathrm{n}$ & 9 & 10 & 10 & 10 & 10 \\
\hline
\end{tabular}

$\mathrm{m}=$ mean, $\mathrm{SD}=$ standard deviation, and $\mathrm{n}=$ number of observations.

TABLE II

Means (m) of Pulmonary Vascular Resistance (Mm $\mathrm{Hg} / 100 \mathrm{ML} / \mathrm{MiN}$ ) UNDER Normoxic CondtTions Before AND After Nitrous Oxide (C) COMPaRed With PVR MEasured DURING AdMINistration OF 25, 50 and 75 PER CENT NITROUS OXIDE

\begin{tabular}{|c|c|c|c|c|c|c|}
\hline & C & $\begin{array}{l}25 \% \\
\text { nitrous } \\
\text { oxide }\end{array}$ & $\mathrm{C}$ & $\begin{array}{c}50 \% \\
\text { nitrous } \\
\text { oxide }\end{array}$ & $\mathrm{C}$ & $\begin{array}{c}75 \% \\
\text { nitrous } \\
\text { oxide }\end{array}$ \\
\hline$\stackrel{\mathrm{m}}{\mathrm{SD}}$ & $\begin{array}{r}16.0 \\
5.5\end{array}$ & $\begin{array}{r}12.9 \\
4.6\end{array}$ & $\begin{array}{r}13.4 \\
4.4\end{array}$ & $\begin{array}{r}11.2 \\
4.3\end{array}$ & $\begin{array}{r}13.2 \\
5.8\end{array}$ & $\begin{array}{r}10.0 \\
4.0\end{array}$ \\
\hline p & \multicolumn{2}{|c|}{$\begin{array}{c}9 \\
<0.001\end{array}$} & \multicolumn{2}{|c|}{${ }^{7}{ }^{7} .01$} & \multicolumn{2}{|c|}{80.001} \\
\hline
\end{tabular}
significance by Student's paired t-test.

TABLE III

Hypoxic Pressor Response. Percentage Increases in Mean Pulmonary A rtery Pressure in Response to Hypoxia During the administration of 25,. 50 and $7 \overline{5}$ Per cent Nitrous Oxide Compared with Means of PekCENTAGE INCREASIES BEFORE AND AFTER (C)

\begin{tabular}{|c|c|c|c|c|c|c|}
\hline & C & $\begin{array}{l}25 \% \\
\text { nitrous } \\
\text { oxide }\end{array}$ & C & $\begin{array}{c}50 \% \\
\text { nitrous } \\
\text { oxide }\end{array}$ & C & $\begin{array}{l}75 \% \\
\text { nitrous } \\
\text { oxide }\end{array}$ \\
\hline$\stackrel{\mathrm{m}}{\mathrm{SD}}$ & $\begin{array}{l}45.1 \\
33.5\end{array}$ & $\begin{array}{l}40.1 \\
48.0\end{array}$ & $\begin{array}{l}52.5 \\
47.3\end{array}$ & $\begin{array}{l}29.4 \\
29.5\end{array}$ & $\begin{array}{l}67.3 \\
41.4\end{array}$ & $\begin{array}{r}25.8 \\
26.0\end{array}$ \\
\hline $\begin{array}{l}n \\
\mathrm{p}\end{array}$ & \multicolumn{2}{|c|}{$\begin{array}{c}8 \\
\text { NS }\end{array}$} & \multicolumn{2}{|c|}{$\begin{array}{c}6 \\
<0.02\end{array}$} & \multicolumn{2}{|c|}{$\begin{array}{c}6 \\
<0.001\end{array}$} \\
\hline
\end{tabular}

Means (m), standard deviation (SD), number of observations ( $n$ ) and statistical significance by Student's paired t-test ( $p$ ).

whilst the pulmonary vasoconstrictor response to alveolar hypoxia was significantly reduced during the administration of 50 per cent and 75 per cent nitrous oxide.

Although the isolated lung preparation is somewhat artificial, it has certain advantages. Pulmonary vascular resistance may be affected by mechanical, circulatory, and neurohumoral factors ${ }^{8}$ and it is impossible to control all these variables in the intact animal. In the isolated lung preparation, peak airway pressures were kept unchanged and a constant end-expiratory pressure was used to minimize atelectasis. The pulmonary blood flow was constant, unlike the intact preparation, where changes in cardiac output can cause marked changes in pulmonary vascular resistance. ${ }^{9}$ If left atrial pressure is below mean alveolar pressure 
HYPOXIC PRESSOR RESPONSE

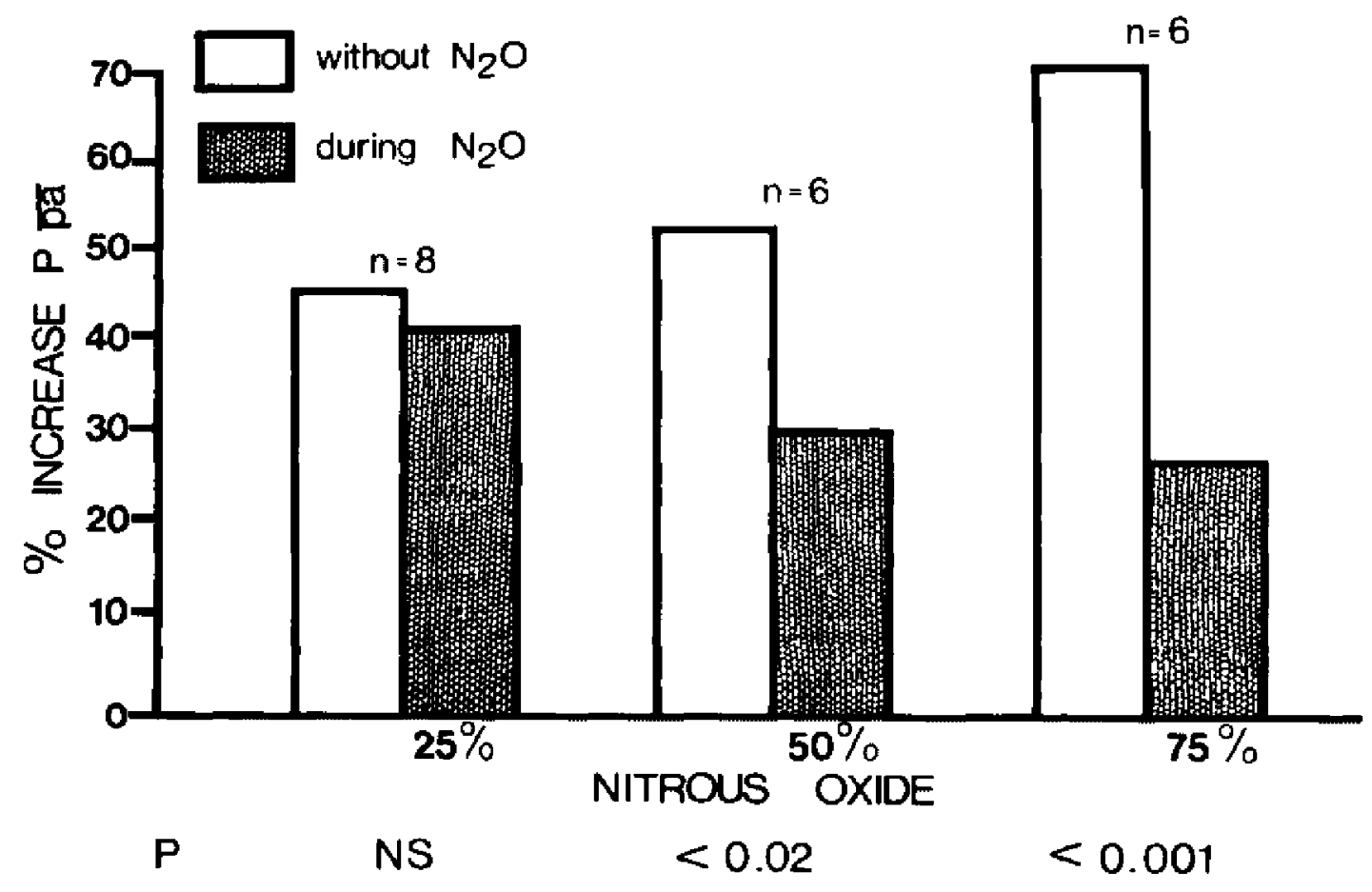

Figune 2. Hypoxic pressor response. A comparison of means of percentage increases in pulmonary artery pressure $\left(P_{\overline{p a}}\right)$ in response to three per cent oxygen inhalation before and after the administration of nitrous oxide, with the response to hypoxia during the administration of nitrous oxide. ( $\mathrm{n}=$ number of observations ). ( $\mathrm{p}=$ statistical significance by Student's paired t-test).

it ceases to be the factor determining the pressure gradient across the pulmonary vascular bed and cannot then be used when calculating pulmonary vascular resistance. ${ }^{10}$ On the other hand, if left atrial pressure rises high enough, it may diminish the hypoxic pressor response. ${ }^{11}$ Accordingly, left atrial pressure was kept constant and at a level which satisfied the above considerations. As the lungs were isolated, central nervous and systemic neurohumoral influences were eliminated. Bronchial blood flow was interrupted so that autonomic activity in the lung was abolished. ${ }^{12}$.

The acid-base status of the pulmonary blood flow can affect both pulmonary vascular resistance ${ }^{13,14}$ and the vasoconstrictor response to alveolar hypoxia. ${ }^{15,16}$ Accordingly $\mathrm{pH}$ and $\mathrm{PCO}_{2}$ were kept within normal limits. The effect of the basal anaesthetic pentobarbitone might be questioned, but this factor was common to all the observations. Furthermore, pentobarbitone has been shown to have little effect on pulmonary vascular resistance in patients, ${ }^{17}$ and in experimental preparations. ${ }^{18}$ It also appears to have little effect on the pulmonary vasoconstrictor response to alveolar hypoxia. ${ }^{19}$

It therefore seemed reasonable to conclude that the observed changes in pulmonary artery pressure represented a change in pulmonary vascular resistance due 


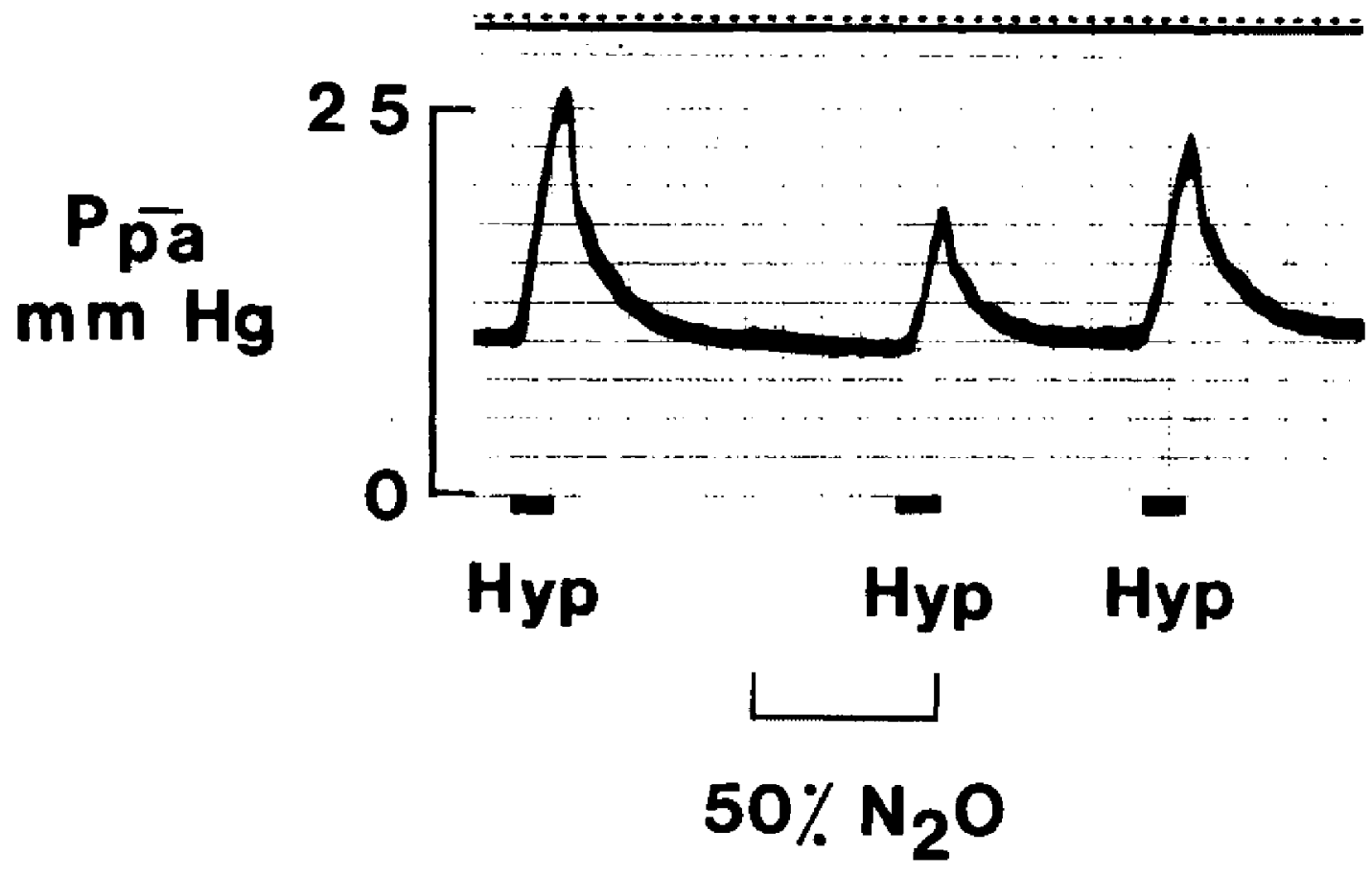

Ficure 3. Mean pulnonary artery pressure $\left(\mathrm{P}_{\overline{\mathrm{DA}}}\right)$ responses to hypoxia ( $\mathrm{Hyp}$ ) before, during and after the administration of 50 per cent nitrous oxide, time marker (top) in minutes.

to vasoconstriction or vasodilatation of the pulmonary vascular bed and that these changes were due to the direct action of nitrous oxide on the pulmonary vasculature or on the hypoxic vasoconstrictor mechanism. However, care is necessary in transferring these results to man, for the action of a drug on the pulmonary circulation depends on the degree of vasomotor tone existing at the time of the experiment ${ }^{20}$ and there are well-known species variations in response to drugs. The reduction in pulmonary vasomotor tone induced by the nitrous oxide must also be taken into account when considering the reduction in pulmonary vasoconstrictor response to alveolar hypoxia. If the pulmonary vascular bed is represented as a series of tubes, the pressure inside the tubes is proportional to the wall tension and inversely proportional to the radius. Hence a given increase in wall tension will produce a smaller increase in intraluminal pressure when the vessels are dilated than when they are constricted. The fact that nitrous oxide caused some degree of background vasodilatation might therefore tend to diminish the subsequent response to alveolar hypoxia, and this may play a part in the decrease in the hypoxic vasoconstrictor response in the presence of this anaesthetic agent. However, Benumof and Wahrenbrock ${ }^{21}$ have demonstrated that nitrous oxide reduces the hypoxic vasoconstrictor response in the left lower lobe preparation of the dog and Sykes, et al. ${ }^{22}$ have demonstrated inhibition of the response in the intact dog, although there is no evidence that nitrous oxide affects pulmonary vascular resistance in this species. ${ }^{23}$ One can therefore presume that in the present preparation there was a different mechanism by which nitrous oxide rendered the pulmonary vasculature less responsive to hypoxia. Indeed, during the administration of 25 per cent nitrous oxide, although there was a significant decrease in pulmonary 
vascular resistance under normoxic conditions, this background vasodilatation was not associated with inhibition of hypoxic vasoconstriction.

Previous studies in the isolated perfused lungs of the cat have shown that the hypoxic pulmonary vasoconstrictor response is reversibly depressed by concentrations of halothane, ether, trichloroethylene and methoxyflurane used clinically. ${ }^{24,25}$ Similar effects have been demonstrated in the isolated rat lung ${ }^{19}$ and in the intact animal trichloroethylene, ether and nitrous oxide have been shown to depress the response to unilateral hypoxia ${ }^{29,20,27}$ whilst in humans both halothane and ether depress the response. ${ }^{28}$ Evidence is therefore accumulating to support the hypothesis that inhalational anaesthetic agents may accentuate the venous admixture effect resulting from ventilation/perfusion inequalities by reversibly depressing the pulmonary vasoconstrictor mechanism, thus increasing the blood flow to hypoxic areas of the lung.

\section{SUMMARY}

Local pulmonary vasoconstriction in response to alveolar hypoxia is a protective mechanism reducing blood flow to poorly oxygenated areas of lung. Pulmonary blood How is thereby directed to better oxygenated lung units and venous admixture and the resulting arterial hypoxaemia is reduced. The effect of nitrous oxide on the pulmonary pressor response to alveolar hypoxia was assessed in the isolated perfused cat lung preparation under conditions of constant flow and constant left atrial and airway pressures. Nitrous oxide, in concentrations of 50 per cent and 75 per cent, was found to produce a reversible depression of the hypoxic pulmonary pressor response. The importance of hypoxia pulmonary vasoconstriction and the possible implications of its reduction by anaesthetic agents are discussed.

\section{RÉSUMÉ}

Une vasoconstriction pulmonaire locale en réponse à une hypoxie alvéolaire représente un mécanisme protecteur, en permettant au flot sanguin pulmonaire d'éviter les régions mal oxygénées du poumon et d'être redirigé vers des régions mieux oxygénées, ceci a comme résultat une diminution du shunt et de l'hypoxémie artérielle.

Nous avons étudié linfluence du protoxyde d'azote sur la réponse vasculaire pulmonaire à l'hypoxie alvéolaire, ceci au moyen d'une préparation animale, soit un poumon de chat, isolé et perfusé à des conditions de débit et de pression auriculaires gauches contants et sous pression gazeuse constante dans les voies aériennes.

Nous avons trouvé que le protoxyde d'azote à des concentrations de 50 et de 75 pour cent produit une dépression réversible de ce réflexe.

L'importance de ce mécanisme est discutée ainsi que les conséquences de sa dépression par les agents anesthésiques.

\section{ACKNOWLEDGEMENTS}

The work was supported by the Medical Research Council (U.K.). Dr. J.B. Hurtig was supported by an Ontario Department of Health Research Fellowship. 


\section{REFERENCES}

1. Bendixen, H.H., Hedley-Whute, J., \& LAver, M.B. Impaired oxygenation in surgical patients during general anesthesia with controlled ventilation. New Engl. J. Med. 269: 991 (1963).

2. Nunv, J.F. Applied respiratory physiology, 1st ed. London: Butterworths, pp. 372 et seq. (1969).

3. Hickey, R.F., Visick, W.D., Fairley, H.B, \& Fourcade, H.E. Effects of halothane anesthesia on functional residual capacity and alveolar-arterial oxygen tension difference. Anesthesiology $38: 20$ (1973).

4. Rehder, K., Sessler, A.D., \& Marsh, H.M. General anesthesia and the lung. Amer, Rev. Resp., Dis. 112: 541 (1975).

5. HuGHES, J.M.B. Lung gas tensions and active regulation of ventilation/perfusion ratios in health and disease. Brit. J. Dis. Chest 69: 153 (1975).

6. Sykes, M.K., Loh, L., Seed, R.F., Kafen, E.R., \& Chakrabartk, M.K, The effect of inhalational anesthetics on hypoxic pulmonary vasoconstriction and pulmonary vascular resistance in the perfused lungs of the dog and the cat. Brit. J. Anaesth. 44: 776 (1972).

7. Revves, J.T. \& Grover, R.F., Blockade of acute hypoxic pulmonary hypertension by endotoxin. J. Appl, Physiol. 36: 328 ( 1974).

8. Nunn, J.F. Applied respiratory physiology, 1st ed. London: Butterworths, pp. 219 et seq. (1969).

9. CarliLl, S.D. \& Duke, H.N. Pulmonary vascular changes in response to variations in left auricular pressure. J. Physiol. (Lond.) 133: 275 (1956).

10. West, J.B., Dolleny, C.T., \& Namare, A. Distribution of blood flow in isolated lung: relation to vascular and alveolar pressures. J. Appl. Physiol. 19: 713 (1964).

11. Benumiof, J.L. \& Wahnesmbock, E.A. Blunted hypoxic pulmonary vasoconstriction by increased lung yascular pressures. J. Appl. Physiol. 38: 846 (1975).

12. Allison, P.R., Daly, I. DE B., \& WaAler, B.A. Bronchial circulation and pulmonary vasomotor nerve responses in isolated perfused lungs. J. Plyysiol. (Lond.) 157: 462 (1961).

13. Barer, G.R., McCukrie, J.R., \& SHaw, J.W. Effect of changes in blood pH on the vascular resistance of the normal and hypoxic cat lung. Cardiovasc. Res. 5; 490 (1971).

14. Herles, F., Kolan, J., KozeNa, J. Regional reactivity of the lung vessels to minute changes of acidity of perfusing fuid, Cardiovasc. Res. 6: 641 (1972).

15. MALIK, A.B. \& KIDD, B.S.L. Independent effects of changes in $\mathrm{H}+$ and $\mathrm{CO}_{2}$ concentrations on hypoxic pulmonary vasoconstriction.. J. Appl. Plyysiol. 34: 318 (1973).

16. Thilenius, O.C. \& Derenzo, C. Effects of acutely induced changes in arterial $\mathrm{pH}$ on pulmonary vascular resistance during nomoxia and hypoxia in awake dogs. Clin. Sci. 42: 277 (1972).

17. Goldyem, S.J., Linde, L.M., Gaal, P.G., Momma, K., Takahashi, M., \& Sarna, G. Effect of barbiturates on pulmonary and systemic haemodynamics. Cardiovascular Res, 2: 136 (1968).

18. Hurtig, J.B. \& Tair, A.R. The effect of barbiturate drugs on pulmonary haemodynamics. In preparation.

19. Bredesen, J.E., Bjentnaes, L.J., \& HavGe, A. Effects of anesthetics on the pulmonary vasoconstrictor response to acute alveolar hypoxia. Microvasc. Res. 10:236 (1975).

20. Silove, E.D. \& Simicha, A.J. Histamine-induced pulmonary vasodilation in the calf: Relationship to hypoxia. J. Appl. Physiol. 35: 830 (1973).

21. Benumof, J.L. \& Wahnenghock, E.A. Local effects of anaesthetics on regional hypoxic pulmonary vasoconstriction. Anesthesiology 43: 525 (1975).

22. SyKes, M.K, HuRtiG, J.B., TAtr, A.R., \& Chakrabarti, M.K. Reduction of hypoxic pulmonary vasoconstriction in the dog during nitrous oxide administration, Brit. J. Anaesth. 49: 301 ( 1977)

23. LOH, L., SEED, R.F., \& SYKES, M.K. The cardiorespiratory effects of halothane, trichloroethylene and nitrous oxide on the dog. Brit. J. Anaesth. 45: 125 (1973).

24. Sykes, M.K., Davies, D.M., Chakrabarti, M.K, \& Loh, L. The effects of halothane, trichloroethylene and ether on the hypoxic pressor response and pulmonary vascular resistance in the isolated perfused cat lung. Brit. J. Anaesth. 45: 655 (1973).

25. Sykes, M.K., Davies, D.M., Loh, L., Jastrzebski, J., \& Chakrabanti, M.K. The effects of methoxyflurane on pulmonary vascular resistance and hypoxic pulmonary vasoconstriction in the isolated perfused cat lung. Brit. J. Anaesth. 48:191 (1976). 
HURTIG, et al.: NITROUS OXIDE AND HYPOXIC PULMONARY VASOCONSTRICTION $\mathbf{5 4 9}$

26. Sykes, M.K., Aninot, R.N., Jastrzebski, J., Gibis, J.M., Obdrzalek, J., \& Huntig, J.B. Reduction of hypoxic pulmonary vasoconstriction during trichloroethylene anaesthesia. J. App. Physiol. 39: 103 ( 1975 ).

27. Sykes, M.K., Hurtic, J.B., Talt, A.R., \& Chakrabarti, M.K. Reduction of hypoxic pulmonary vasoconstriction during ether anaesthesia in the dog. Brit. J. Anaesth. 49: 293 (April 1977).

28. B Jertnaes, L.J., Hauge, A., Nakken, K.F., \& Bhedesen, J.E. Hypoxic pulmonary vasoconstriction: inhibition due to anaesthesia. Acta Physiol. Scand. 96:283 (1976). 